\title{
Deep cleaning mouthwashes, no stain!
}

Curasept ADS is a professional range of chlorhexidine mouthwashes, available from J\&S Davis.

With your guidance, patients can use them to fight gum conditions, with a variant to suit their needs.

The range includes:

$\rightarrow$ Curasept ADS Implant, to support healing and tissue repair

$\rightarrow$ Curasept ADS Perio, for people with periodontal problems and who are undergoing perio treatment

$\rightarrow$ Curasept ADS 220, the most popular! An intensive mouthwash, also based on the patented Anti Discolouration System

(ADS) found in all Curasept products, to reduce staining.

For more information on the industryleading products available from J\&S Davis, visit www.js-davis.co.uk, call 01438747344 or email jsdsales@js-davis.co.uk.

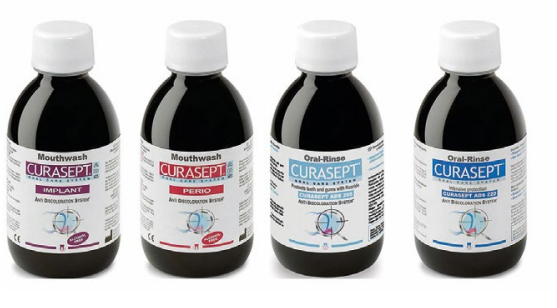

\section{The only solution!}

From COLTENE, CanalPro solutions for irrigation will support successful endodontic outcomes.

Canals must be thoroughly cleansed to proceed safely, and you want this part of the process to be as efficient as it is safe.

CanalPro $\mathrm{NaOCl}$ for root canal irrigation is available in both a $3 \%$ and $6 \%$ formula. It has been engineered to deliver comprehensive irrigation/ debridement, during and after instrumentation, for upgraded, predictable and stable root canal therapy.

This is just one of the CanalPro products available from COLTENE, joining the revolutionary Jeni, for autonomous digital navigation in the endo canal.

For more on COLTENE, visit www. coltene.com, emailinfo.uk@coltene.com or call 08002545115 .

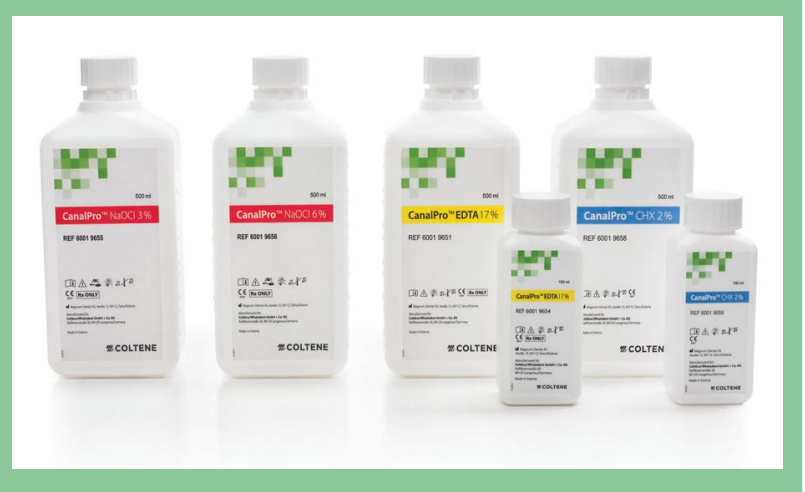

The secret to an

\section{exceptional clean}

What's the secret to achieving exceptionally clean interdental spaces? Using CPS interdental brushes with patented, ultra-fine Cural bristles. This creates an umbrella effect during use to ensure an effective yet atraumatic clean between the teeth and along the gum line.

Dental professionals can recommend the colourful CPS range of interdental brushes with complete confidence knowing that they can be used with natural teeth and dental restorations, including implants.

Available in a variety of different sizes to suit every patient, CPS interdental brushes also come with a long service life, thanks their reusable handles and replaceable brush heads..

For more information call 01480 862084, email info@curaprox.co.uk or visit www.curaprox.co.uk.

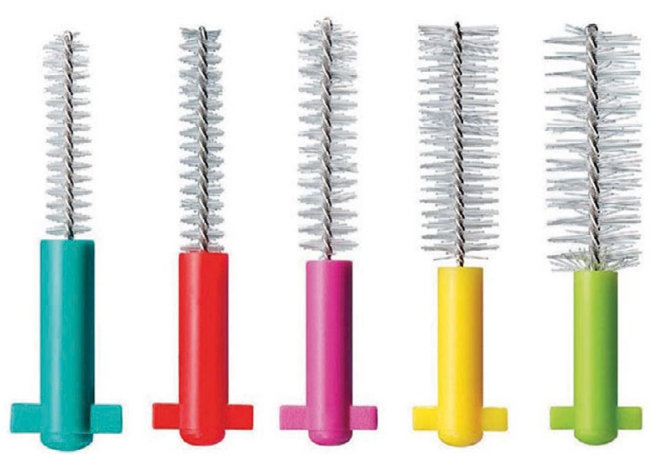

\section{Time, strength and peace of mind}

Kemdent Diamond Carve is a handmixed glass ionomer cement providing a highly aesthetic alternative to traditional composite, glass ionomer or amalgam restorations. It is ideal for posterior, nonloading bearing Class I and II indications, as well as Class V abrasion cavities, deciduous teeth restorations, core build-ups and amalgam repairs.

Its lack of dimensional change during chemical curing means it can be placed in one increment for significant time-saving advantages. These are further supported by the material's ability to bond to both enamel and dentine without the need for acid etching.

For complete peace of mind, Kemdent Diamond Carve is radiopaque, features no polymerisation shrinkage or cracking and displays much higher compressive strength than most conventional glass ionomers.

For more information about the leading solutions available from Kemdent visit www.kemdent.co.uk or call 01793770256.

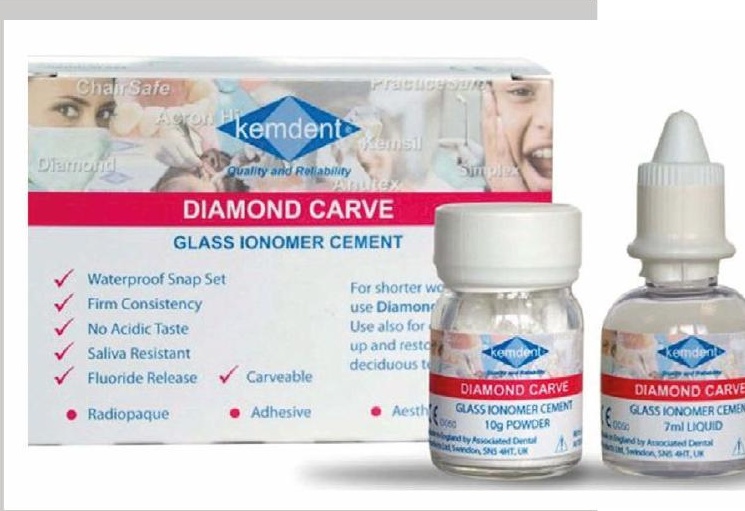

